\title{
Particulate Trace Metals from Shallow Hydrothermal Vents
}

\author{
MARIA-ELENA VORRATH ${ }^{1}$, DAVID GONZÁLEZ- \\ SANTANA $^{2}$, VERÓNICA ARNONE ${ }^{3}$, MATTHIEU \\ BRESSAC $^{4}$, YOAN GERMAIN ${ }^{5}$, FLORIANE DESPREZ DE \\ DESINCOURT $^{1}$, GERALDINE SARTHOU ${ }^{1}$ AND HÉLÈNE \\ PLANQUETTE $^{1}$ \\ ${ }^{1}$ University Brest, CNRS, IRS \\ ${ }^{2}$ CNRS, Univ Brest, LEMAR \\ ${ }^{3}$ Instituto de Oceanografía y Cambio Global (IOCAG), \\ Universidad de Las Palmas de Gran Canaria (ULPGC) \\ ${ }^{4}$ Sorbonne Université, CNRS, Laboratoire d'Océanographie de \\ Villefranche \\ ${ }^{5}$ IFREMER, centre de Brest, REM/GM/LCG \\ Presenting Author: MariaElena.Vorrath@univ-brest.fr
}

Distribution of bioactive, particulate trace metals (pTMs) from shallow hydrothermal vents (SHVs) are still poorly investigated. Exchange processes with the dissolved phase and the subsequent impact on TM marine biogeochemical cycling remain unclear. Here, we document the abundance and distribution of pTMs around SHVs investigated during the TONGA cruise (GEOTRACES GPpr14) in late 2019 along two active SHVs in the Western Tropical South Pacific. Prior to sampling, the bathymetry of the SHVs "Volcano 1 " $\left(21^{\circ} \mathrm{S}, 176^{\circ} \mathrm{E}\right)$ and "Simone" $\left(20^{\circ} \mathrm{S}, 175^{\circ} \mathrm{E}\right)$ was intensively surveyed and multibeam echo sounder and numerous CTDs (physical parameters and gases) were used to identify the source of hydrothermal activity. Additionally, areas outside the possible range of the SHV plumes were sampled. Preliminary results show high concentrations from bioactive, particulate pTMs, e.g. $\mathrm{Mn}$ and Fe close to "Volcano 1" at $125 \mathrm{~m}$ depth propagating westward along the current. At "Simone", a hydrothermal plume appears with lower pTM concentrations in deeper depths. We will discuss these two different systems and their potential impact on surface productivity. 